\title{
Article \\ Effect of the Anodizing Temperature on Microstructure and Tribological Properties of 6061 Aluminum Alloy Anodic Oxide Films
}

\author{
Feng Guo ${ }^{1}$, Yongzhi Cao ${ }^{1}$, Kaijie Wang ${ }^{1}$, Peng Zhang ${ }^{1,2, *}$, Yaowen Cui ${ }^{1}$, Zhenjiang Hu ${ }^{1}$ and Zhiwen Xie $^{3}$ \\ 1 Center for Precision Engineering, Harbin Institute of Technology, Harbin 150001, China; gfustl@126.com (F.G.); \\ cflying@hit.edu.cn (Y.C.); whl_wkj@163.com (K.W.); yaowen.cui897@gmail.com (Y.C.); \\ lyhoo@hit.edu.cn (Z.H.) \\ 2 Chongqing Research Institute, Harbin Institute of Technology, Chongqing 401135, China \\ 3 Liaoning Key Laboratory of Complex Workpiece Surface Special Machining, University of Science and \\ Technology Liaoning, Anshan 114051, China; xzwustl@126.com \\ * Correspondence: zp@hit.edu.cn; Tel.: +86-451-86412924
}

check for updates

Citation: Guo, F.; Cao, Y.; Wang, K.; Zhang, P.; Cui, Y.; Hu, Z.; Xie, Z. Effect of the Anodizing Temperature on Microstructure and Tribological Properties of 6061 Aluminum Alloy Anodic Oxide Films. Coatings 2022, 12, 314. https://doi.org/10.3390/ coatings12030314

Academic Editor: Maria

Vittoria Diamanti

Received: 28 January 2022

Accepted: 23 February 2022

Published: 27 February 2022

Publisher's Note: MDPI stays neutral with regard to jurisdictional claims in published maps and institutional affiliations.

Copyright: (C) 2022 by the authors. Licensee MDPI, Basel, Switzerland. This article is an open access article distributed under the terms and conditions of the Creative Commons Attribution (CC BY) license (https:// creativecommons.org/licenses/by/ $4.0 /)$.

\begin{abstract}
Anodizing a simple and effective method to improve the wear resistance of 6061 aluminum alloy. In this study, the microstructure of 6061 aluminum alloy oxide films (AAO) was adjusted by changing the electrolyte temperature $\left(5,15\right.$, and $\left.25^{\circ} \mathrm{C}\right)$ using $160 \mathrm{~g} / \mathrm{L}$ sulfuric acid as the electrolyte. The phase composition, microstructure, and morphological characteristics of the specimens were detected using X-ray diffractometer and field emission scanning electron microscopy (SEM). The hardness, elastic modulus, and tribological properties of the films were examined using hardness testers and a rotary friction tester. The results showed that as the temperature of the electrolyte increases, the surface of the oxide films changes from uniformly distributed small-sized pores to a coral-like loose porous structure, and the thickness of the films increases. The electrolyte temperature has a significant effect on the friction performance of the AAO films. When the solution temperature decreases from 25 to $5{ }^{\circ} \mathrm{C}$, the steady-state friction coefficient decreases from 0.46 to 0.39 . According to the morphology of the wear tracks, it can be determined that the main wear mechanism of AAO films gradually changes from delamination wear to abrasive and adhesive wear, and the wear rate drops by $\sim 69 \%$.
\end{abstract}

Keywords: 6061 aluminum alloy; anodization; microstructure; friction and wear

\section{Introduction}

Aluminum is the most abundant metallic element in the earth's crust. The low density, high specific strength, excellent thermal conductivity, and corrosion resistance of aluminum and its alloys (Al-Cu, Al-Mg, Al-Mg-Si and Al-Zn) are promoting the development of aerospace, construction, automobile, shipbuilding, controllable fusion technology and chemical industries [1-4]. The Mg and Si elements in 6061 aluminum alloy (Al-Mg-Si) improve the plasticity, weldability, and processability of the material, making the 6061 aluminum alloy widely used in electrical fixtures and electronic precision instruments, aerospace, and automotive structural parts [5-7]. Although aluminum alloys are prone to form an oxide layer in the atmospheric environment, the primary oxide layer is only a non-uniform structure of tens to hundreds of angstroms, resulting in low hardness and poor wear resistance of 6061 aluminum alloy [8-11]. Currently, micro-arc oxidation, anodizing, plasma electrolytic oxidation, enameling, painting, and electroplating are often used in industry to improve the surface performance and service life of aluminum alloys [12,13]. Anodizing has become the most promising preparation technology of aluminum alloy films because of its low cost, excellent film performance, functionality, and colorability. In the process of anodizing, electrochemical reactions occur on the surface of aluminum alloy. 
$\mathrm{Al}^{3+}, \mathrm{O}^{2-}$, and $\mathrm{OH}^{-}$ions pass through the substrate surface under the action of the electric field to form an anodic oxide film (AAO), which consists of a thin barrier layer as well as a thick porous layer $[14,15]$.

The micro-nano structure of the $\mathrm{Al}_{2} \mathrm{O}_{3}$ porous layer is of great significance to the mechanical and tribological properties of aluminum alloy [16]. Generally, the microstructure and thickness of the AAO film depend greatly on the electrolyte composition, temperature, $\mathrm{PH}$ value, and concentration, as well as the time, current density, and voltage of the anodizing process. The regular and continuous hexagonal cell structure, smaller pore size and porosity obtained by adjusting the anodizing process parameters can significantly improve the mechanical and tribological properties of the AAO [17]. Minjoong Kim et al. [18] generated 6061 oxide films by adjusting the temperature $\left(0,5,10,15\right.$, and $\left.20^{\circ} \mathrm{C}\right)$ of the phytic acid electrolyte. The experimental results showed that with the increase of temperature, the density of AAO decreased, the thickness of AAO increased from 2.26 to $28.32 \mu \mathrm{m}$, and the current density increased from 14.55 to $23.38 \mathrm{~mA} / \mathrm{cm}^{2}$. S. Theohari et al. [19] found that the magnesium doped in the barrier layer hindered the growth of the oxide layer during the preparation of AA5052 oxide films. A.A. Poznyak et al. [20] investigated the relationship between oxide growth, dissolution and oxide volume expansion in porous aluminum films. The results indicated that the increase of $\mathrm{OH}$ in the oxide film formed at high current density contributes to the expansion of the oxide film, oxide dissolution, and volume expansion increase with the increase of current density. Zhisheng Wang et al. [21] found that the grain size of 6061 aluminum alloy was large, and the second phase particles were distributed inside the grains. After sulfuric acid anodization, the mechanical properties of the anodic oxide films were significantly improved compared to substrates. Tsung-Chieh Cheng et al. [22] prepared anodic oxide films on 6061-T6 aluminum alloy specimens by adjusting the substrate surface roughness, electrolyte concentration, and anodizing voltage. In their study, 0.3 M sulfuric acid electrolyte was selected, and the experimental results showed that the polishing process had a great effect on the quality and stability of anodic oxide films. In addition, in the range of 30 to $50 \mathrm{~V}$, the electrochemical reaction rate and the mechanical properties of oxide film increased with the increase of voltage. However, when the voltage continued to increase to $60 \mathrm{~V}$, the occurrence of cracks reduced the mechanical properties of the films. I.C. Chung et al. [23] prepared AA6061 oxide films in $\mathrm{H}_{2} \mathrm{SO}_{4}$ electrolyte solutions with a concentration of $1-5 \mathrm{M}$ and a current density of $0.3-3 \mathrm{~A} / \mathrm{dm}^{2}$. The results showed that the growth rate of the oxide layer increased with the increase of current density and electrolyte concentration. However, when the current density and electrolyte concentration was in the range of $1-3 \mathrm{~A} / \mathrm{dm}^{2}$ and 3-5 M, respectively, the quality of the $\mathrm{Al}_{2} \mathrm{O}_{3}$ layer gradually deteriorated, and the protective ability to substrate also decreased. Hyo-sang Kim et al. [17] performed reciprocating friction and wear experiments on AAO films with different pore diameters $(28,45,95$, and $200 \mathrm{~nm})$ under light loads $(1 \mathrm{mN}-1$ $\mathrm{N})$. The results indicated that the larger the pore size, the higher the friction coefficient of the films, and under wear conditions from 1 to $10 \mathrm{mN}$, only slight plastic deformation occurred on the surface, while under conditions from $10 \mathrm{mN}$ to $1 \mathrm{~N}$, a thicker smooth film formed by a combination of friction-induced chemical reactions and debris formed by the compaction of the AAO appeared at the contact interface. The smooth film improved the tribological properties of the AAO. According to the research results of Seyyed Hasan Mohitfar et al. [24], the weight loss of the 6061-T6 aluminum alloy hard anodic oxide film prepared in the sulfuric acid electrolyte on the ball-on-disk tribometer was only two percent of the substrate wear. Krishna et al. [25] found that the wear resistance of oxide films was significantly higher than that of 6061-T6 aluminum alloy substrates under a $2 \mathrm{~N}$ normal load. Despite extensive studies on aluminum alloy anodizing parameters, due to the numerous influencing parameters in the aluminum alloy anodizing process, in-depth study on the effect of electrolyte temperature changes on the performance of anodic oxide films is still lacking.

This paper aims to explore in-depth the effect of electrolyte temperature on the quality of 6061 aluminum alloy anodic oxide films. The composition, microstructure, and wear 
track morphology of the porous oxide films were characterized by X-ray diffractometer and field emission scanning electron microscopy, respectively. The hardness of the oxide films was measured using the Vickers hardness tester and nano hardness tester. The tribological properties of the oxide films were tested and characterized by a ball-on-disc tribometer. A strong correlation between preparation temperature, microstructure, mechanics, and tribology of 6061 aluminum alloy anodic oxide films was established. This study provides a theoretical basis for the further development of aluminum alloy anodizing technology.

\section{Materials and Methods}

\subsection{Materials and Pretreatment}

The 6061 aluminum alloy substrate was processed by wire cutting into cubes of $20 \mathrm{~mm} \times 20 \mathrm{~mm} \times 5 \mathrm{~mm}$. The substrate composition is shown in Table 1 . The pretreatment process started with sanding the specimens using water-resistant sandpaper with different items (800\#/1500\#/2000\#) and polishing to obtain a smooth surface, followed by ultrasonic degreasing in a room temperature solution containing surfactants for $2 \mathrm{~min}$. Then, specimens were immersed in a deoxidizing solution at room temperature for $5 \mathrm{~min}$. Finally, we neutralized them in a mixture of nitric acid and hydrogen peroxide for $2 \mathrm{~min}$. After the pretreatment process, it was ensured that continuous water films could be formed on the surface of 6061 aluminum alloy.

Table 1. The elemental composition of 6061 aluminum alloy (wt $\%)$.

\begin{tabular}{ccccccc}
\hline $\mathbf{M g}$ & $\mathbf{S i}$ & $\mathbf{F e}$ & $\mathbf{C u}$ & $\mathbf{Z n}$ & $\mathbf{T i}$ & $\mathbf{A l}$ \\
\hline $0.8-1.2$ & $0.4-0.8$ & $\leq 0.7$ & $0.15-0.4$ & 0.25 & 0.15 & Bal. \\
\hline
\end{tabular}

\subsection{Anodizing}

The anodic oxide films were prepared on the surface of 6061 aluminium alloy using a $15 \mathrm{~V}$ pulsed power supply, during which the current density was automatically varied to maintain a constant supply voltage. A concentration of $160 \mathrm{~g} / \mathrm{L}$ sulfuric acid solution was selected as the electrolyte. The temperature of the electrolyte was controlled at 5, 15, and $25{ }^{\circ} \mathrm{C}$, respectively, and the duration of the anodizing process was $45 \mathrm{~min}$. The distance between the vertically immersed aluminum alloy anode and the aluminum cathode was $3 \mathrm{~cm}$, and the electrolyte was electrically stirred during the experiment. The anodizing process was an exothermic process, therefore, using a cooling system to control the temperature of the electrolyte solution within a small fluctuation range was necessary [26].

\subsection{Structure and Composition and Anodic Films}

In this experiment, an X-ray diffractometer (XRD, X' Pert Powder, PANalytical B.V., Almelo, Holland) was used to analyze the structure of the AAO. The range of $2 \theta$ was between $10^{\circ}$ and $90^{\circ}$, and the scanning speed was $10^{\circ} / \mathrm{min}$. The chemical composition of the AAO was collected by an energy dispersive spectrometer (EDS, XFlash61100 Bruker, Karlsruhe, Germany).

\subsection{Microhardness and Tribological}

A Vickers hardness (HV-1000, Laizhou Laishi Test Equipment Co., Ltd., Laizhou, China) and nanoindentation tester (G200, Keysight Technologies, Beijing, China) were used to measure the Vickers hardness and nanohardness of the oxide films, respectively. The Vickers hardness test parameter was $0.05 \mathrm{~N}$ and maintained for $15 \mathrm{~s}$. The nanoindentation detection depth was 1 micron, and 20 nanoprobes were pressed into the area to be tested in a $4 \times 5$ matrix. The wear test used an ambient temperature rotary friction and wear tester (MS-T3000, Lanzhou Huahui Instrument Technology Co., Ltd., Lanzhou, China). The friction test parameters are shown in Table 2. The wear rate $k$ is calculated according to the Formula (1), where $V$ represents the amount of wear calculated from the size of the wear 
track $\left(\mathrm{mm}^{3}\right), S$ and $L$, respectively, represent the sliding distance $(\mathrm{m})$ and the applied load $(\mathrm{N})$. The above tests were repeated several times to obtain accurate values.

$$
k=V /(S \cdot L)
$$

Table 2. Testing parameters of wear process.

\begin{tabular}{cccccc}
\hline Ball Material & Ball Diameter & Wear Diameter & Sliding Time & Sliding Speed & Force \\
\hline $\mathrm{Si}_{3} \mathrm{~N}_{4}$ & $6 \mathrm{~mm}$ & $12 \mathrm{~mm}$ & $10 \mathrm{~min}$ & $200 \mathrm{r} / \mathrm{min}$ & $5 \mathrm{~N}$ \\
\hline
\end{tabular}

\subsection{Morphology}

A field emission scanning electron microscope (SEM, EVO MA 10, Carl Zeiss AG, jena, Germany) was used to characterize the microstructure of the surface and interface of the $\mathrm{AAO}$ and the morphology of the wear track. The diameter of the oxide film pores was measured by Image J software.

\section{Results}

Figure 1 shows SEM images of surfaces of 6061 aluminum alloy anodic oxide films prepared at the electrolyte temperature of 5,15 , and $25^{\circ} \mathrm{C}$, which clearly show the surface microstructure of the three specimens. As shown in Figure 1a, the surface of the AAO formed at the electrolyte temperature of $5{ }^{\circ} \mathrm{C}$ has a smooth surface and a relatively dense structure. The uniformly small pits on the surface are pores with a diameter of approximately 6-12 nm, large pore spacing and thick pore walls. The steady-state current of this anodizing was $0.4 \mathrm{~A}$. The existence of large-scale defects on the surface of the oxide film was mainly due to the presence of second phase particles in the 6061 aluminum alloy, which hindered the growth of the film layer. As a result, the initial electric field at the second phase particles on the surface of the substrate was weaker and the growth of the oxide layer was slower than at the position of the aluminum substrate. After the AAO covered the second phase particles, the growth rate of the oxide film recovered. This phenomenon eventually led to the formation of partial defects on the surface of oxide films. Studies have shown that the applied potential was directly related to the pore size of the porous layer [16]. Under the condition of constant potential, porous layers of different specimens had similar pore diameters as the temperature of the electrolyte increased. When the electrolyte temperature rose to $15^{\circ} \mathrm{C}$, the steady-state anodizing current rose to $0.9 \mathrm{~A}$, and a rough-texture structure appeared on the surface of the oxide film, as shown in Figure 1b. During the growth of oxide film, the oxidation current usually causes the generation of oxygen bubbles $\left(2 \mathrm{O}^{2-} \rightarrow\right.$ $\left.\mathrm{O}^{2}+4 \mathrm{e}^{-}\right)$. The increase in steady-state current led to an increase in oxygen bubbles on the surface of the 6061 aluminum alloy, and the release of small-scale oxygen bubbles reduced the density of the pore wall $[27,28]$. Therefore, the pore size and spacing of the AAO were similar to the specimen shown in Figure 1a. However, when the temperature reached $25^{\circ} \mathrm{C}$, the steady-state current reached 2.4 A and porous coral-like structures appeared on the surface of the oxide film as shown in Figure 1c. With the further increase of the steady-state current, the release of oxygen bubbles on the surface of the substrate provided a condition for the formation of loose porous AAO. In addition, with the increase of temperature, the transmission of $\mathrm{Al}^{3+}$ and $\mathrm{O}^{2-}$ ions at the electrolyte/film interface accelerated, and the dynamic equilibrium process of growth and dissolution of oxide films also accelerated. Considering comprehensively, the temperature-induced increase in current and oxygen release as well as the acceleration of ions migration had a significant effect on the density of oxide films, resulting in loose porous structures of the AAO film when the temperature reached $25{ }^{\circ} \mathrm{C}$. 


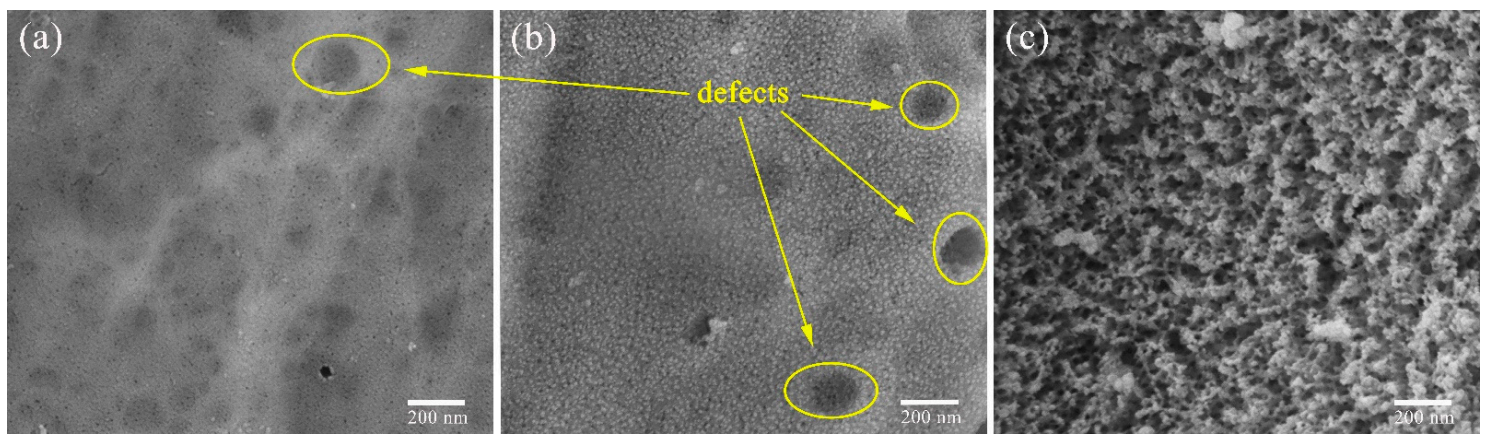

Figure 1. Surface microstructure images of 6061 aluminum alloy oxide films at different sulfuric acid electrolyte temperatures: (a) $5^{\circ} \mathrm{C},(\mathbf{b}) 15^{\circ} \mathrm{C}$, (c) $25^{\circ} \mathrm{C}$.

The cross-sectional SEM morphology and elemental energy spectrum of the 6061 aluminum alloy anodic oxide layers are shown in Figure 2. Due to the large difference in film thickness, different magnification factors were used in different cross-sectional morphology pictures. As shown in Figure 2b,c, the thickness of the oxide layer became thicker, and the pit-like defects of the cross-sectional morphology increased as the temperature of the electrolyte increased. The thickness of the AAO prepared at 5,15 , and $25{ }^{\circ} \mathrm{C}$ was 3.2 , 8.4 , and $24.6 \mu \mathrm{m}$, respectively. The large difference in film thickness was due to the fact that in the anodizing process, limited by the size of the specimens, the film was driven upwards during the growth process, and the migration of ions accelerated with the increase in electrolyte temperature. When the AAO grew vertically to the substrate, the growth rate of the oxide film in the high-temperature electrolyte was much faster than that in the low-temperature electrolyte. Therefore, as the temperature increased, the driving force to promote the longitudinal growth of the oxide film increased with the increase in the overflow of oxygen bubbles and the acceleration of the electrochemical reaction. This ultimately led to an increase in oxide film thickness, while reducing surface pore density and increasing cross-sectional defects.

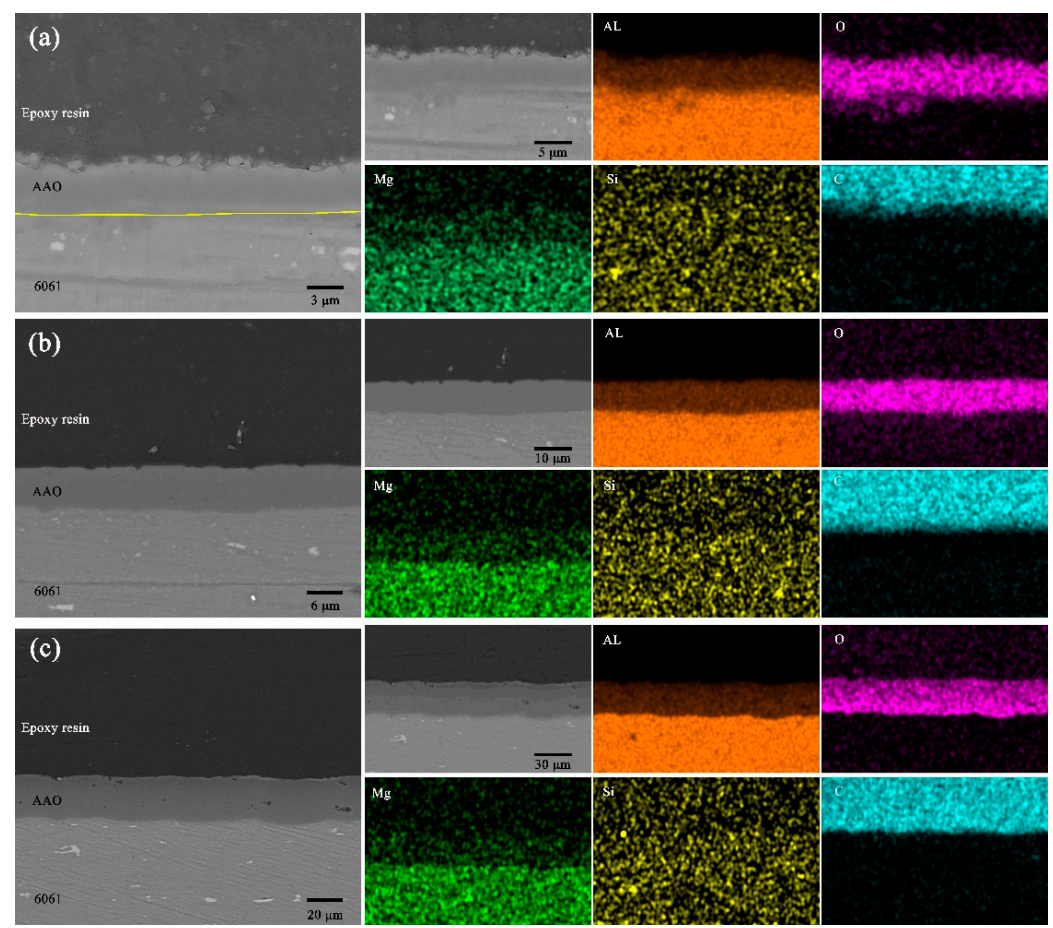

Figure 2. Cross-sectional and elements mapping SEM images of 6061 aluminum anodized alloy films: (a) $5{ }^{\circ} \mathrm{C},(\mathbf{b}) 15^{\circ} \mathrm{C},(\mathbf{c}) 25^{\circ} \mathrm{C}$. 
The X-ray diffraction patterns of the three specimens are shown in Figure 3, indicating the presence of a wide diffraction peak near $22^{\circ}$ of the XRD curves. This implied that the films produced by anodization were non-crystalline [29,30]. In addition, the sharp diffraction peaks reflected the presence of the aluminum phase, indicating that the X-rays were able to penetrate the non-crystal oxide layer. The diffraction intensities of the oxide films formed at the electrolyte temperature of 515 , and $25{ }^{\circ} \mathrm{C}$ at the diffraction peak of $44.6^{\circ}$ were $9501,10,133$, and 13,888 a.u., respectively. The diffraction intensity of the thicker oxide film prepared at $25{ }^{\circ} \mathrm{C}$ was higher, indicating that the film prepared in the high-temperature electrolyte can transmit more X-rays than the film prepared in the lowtemperature electrolyte, further confirming that the density of the oxide layer decreased as the electrolyte temperature increased.

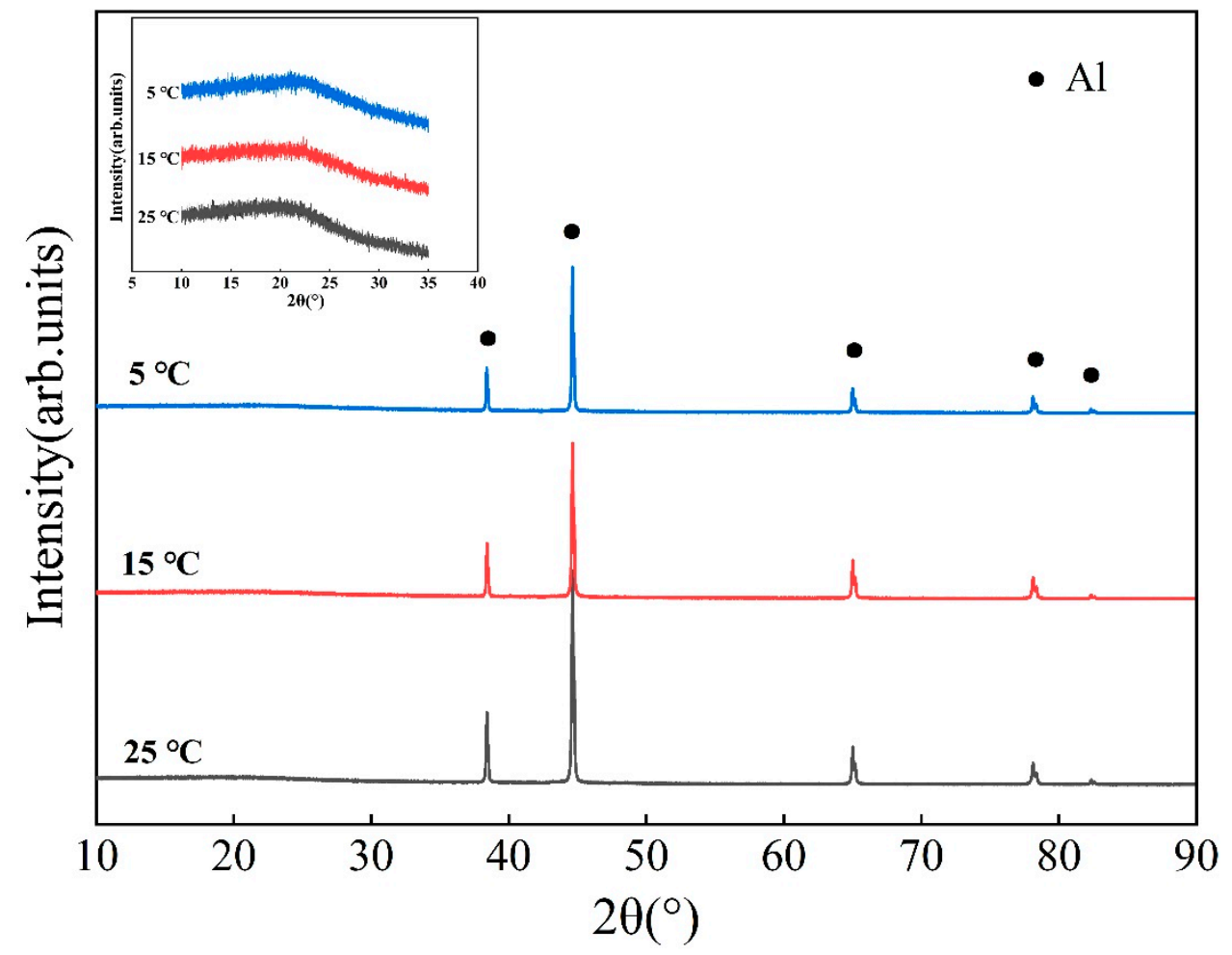

Figure 3. X-ray diffraction pattern of the AAO prepared under different temperature environments. The subgraph is the $10^{\circ}-35^{\circ}$ diffraction pattern.

The Vickers hardness, nano-hardness, and elastic modulus of aluminum alloy anodic oxide films prepared at different electrolyte temperatures are shown in Figure 4 . The indenter applied pressure in a direction perpendicular to the surface of the films. The Vickers hardness $\left(\mathrm{Hv}_{0.05}\right)$, nano-hardness, and elastic modulus of the oxide film prepared at $5{ }^{\circ} \mathrm{C}$ were $171.7 \pm 2.6,5.05 \pm 0.42$, and $100.40 \pm 8.7 \mathrm{GPa}$, respectively. When the electrolyte temperature rose to $15^{\circ} \mathrm{C}$, the Vickers hardness, nano-hardness, and elastic modulus of the oxide film were $166.6 \pm 3.7,4.92 \pm 0.37 \mathrm{GPa}$, and 103.6 $\pm 9.5 \mathrm{GPa}$, respectively. However, the oxide film prepared at $25^{\circ} \mathrm{C}$ had a loose and porous structure, so accurate data could not be obtained when measuring the nano-hardness and elastic modulus. The Vickers hardness value of the specimen was $166.4 \pm 5.6$. It was worth noting that when measuring the Vickers hardness with a diamond indenter, the indentation morphology of the dense oxide film prepared at $5^{\circ} \mathrm{C}$ was a regular diamond shape. However, as the experimental temperature increased, the density of the oxide film decreased, and the indentation morphology was an irregular diamond shape similar to a circle, which may lead to the actual hardness being slightly lower than the measured value. 


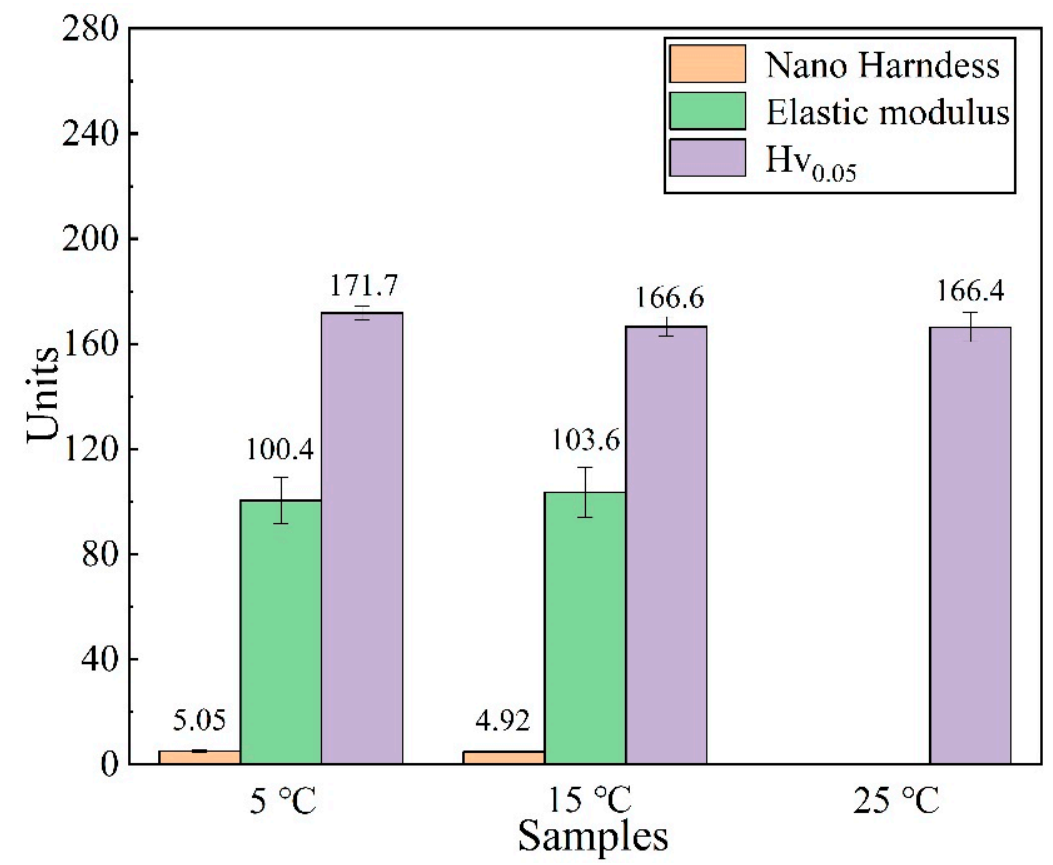

Figure 4. Hardness and elastic modulus of the AAO.

The wear track morphology of the AAO was observed by a scanning electron microscope, and different magnifications were chosen for the different images to reveal the wear mechanism more accurately. The AAO had obvious wear damage marks, grooves, and cracks during the wear test, but the oxide layer did not fall off, which indicated that the AAO had a protective effect on the substrate. When the micro-convex structure of the AAO surface slid relative to the grinding ball, agglomerated micro-particles appeared at the contact interface, and finally plastically deformed under the load to form a thin friction layer. The thinner AAO film was susceptible to the effect of the substrate material during the friction test, with a significant agglomerated micro-particles transferring and smearing phenomenon at the contact interface, as shown in Figure 5a [17]. The center of the wear track of the denser and thicker AAO film was smooth and regular, and only a few fragments appeared at the edge of the wear track. The generation of fragments was related to the surface quality of the films, as shown in Figure 5b. However, as shown in Figure $5 c$, obvious film peeling occurred on the wear track of the AAO films, accompanied by large cracks and grooves. In order to further explore the wear mechanism of oxide films on the three specimens, the wear track was partially enlarged. In Figure 5d,e, the cyclic friction stress of the AAO film under $5 \mathrm{~N}$ load exceeded the yield strength of the material, and cracks appeared on the wear track. Due to the compactness and plasticity of the oxide film, the phenomenon of large-area film peeling around cracks will not occur. The wear mechanism of the oxide film was abrasive and adhesive wear. During the wear process, the porous AAO film was compacted, and a thick friction layer was formed under the action of the load as shown in Figure 5f. The gradual accumulation of cyclic stresses caused cracks on the surface of the AAO film, which gradually expanded and led to flake or block shedding of friction layer. The wear mechanism is typical delamination wear [31]. 

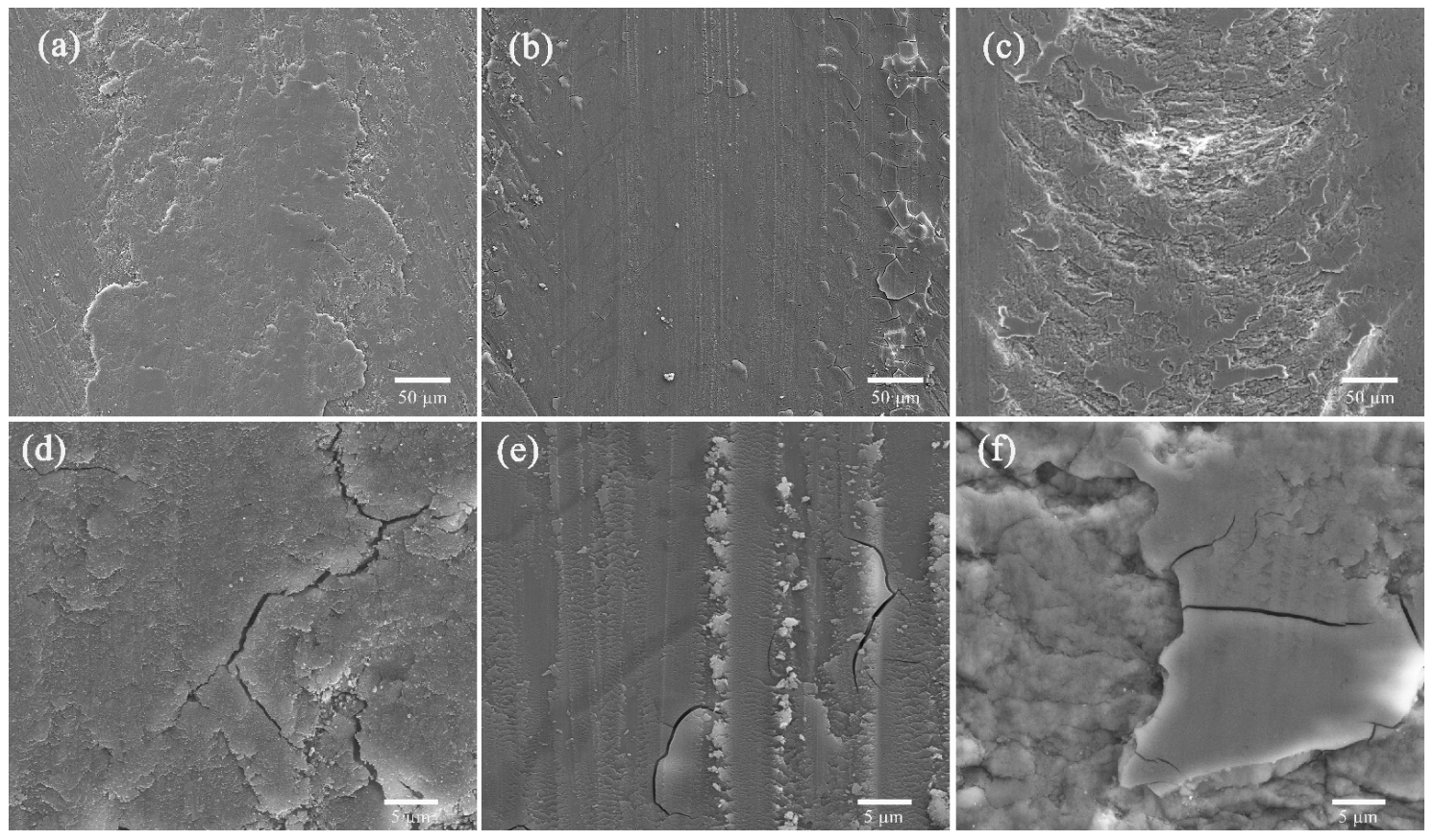

Figure 5. Scanning electron micrograph of the wear track of the AAO; slow magnification: (a) $5{ }^{\circ} \mathrm{C}$ (b) $15{ }^{\circ} \mathrm{C}$, (c) $25^{\circ} \mathrm{C}$; high magnification: (d) $5{ }^{\circ} \mathrm{C},(\mathbf{e}) 15^{\circ} \mathrm{C},(\mathbf{f}) 25^{\circ} \mathrm{C}$.

To explore the tribological characteristics of the AAO films in-depth, the evolution curves of the friction coefficient of the three specimens were plotted, as shown in Figure 6. The trends of the curves were very obvious, including the break-in period where the friction coefficient rises slowly and the steady-state wear period where the friction coefficient fluctuates within a small range. As shown in Figure $6 a, b$, the initial value of the friction coefficient was lower than 0.2 , and as the friction coefficient increased, the friction process steadily transitioned to the steady-state wear stage. In the steady-state wear stage, the friction coefficient fluctuates little and the wear processes were smooth. The steady-state friction coefficients were 0.39 and 0.40 , respectively. However, in Figure $6 c$, the initial friction coefficient during the break-in period was about 0.3 , and the friction coefficient fluctuated greatly and was accompanied by severe wear during the coefficient rising and steady-state wear stage. The steady-state friction coefficient was 0.46 . Studies have shown that the friction coefficient of AAO films increases with increasing porosity [17]. Therefore, during the wear experiments, the continuous dense film layer had a significant friction reduction effect, while the loose and porous films, due to the micro-concave structure, hindered the relative sliding of the grinding balls against the AAO films, resulting in a higher friction coefficient. The high load during the friction test caused the surface friction layer to chip and peel off, which was also one of the main reasons for the large fluctuation of the friction coefficient.

The wear track cross-sectional profiles of the three specimens and the corresponding wear rate are shown in Figure 7. As shown in Figure 7a,b,d, the uniform AAO films showed excellent wear resistance during the wear test. The average depth, width, and wear rate of the wear track were $2.41 \mu \mathrm{m}, 304.5 \mu \mathrm{m}, 1.11 \pm 0.11 \mathrm{~mm}^{3} \cdot \mathrm{N}^{-1} \cdot \mathrm{m}^{-1}$ and $2.48 \mu \mathrm{m}, 317.3 \mu \mathrm{m}$, $1.19 \pm 0.09 \mathrm{~mm}^{3} \cdot \mathrm{N}^{-1} \cdot \mathrm{m}^{-1}$, respectively. When the electrolyte temperature increased to $25^{\circ} \mathrm{C}$, the large-area peeling on the surface of the wear track led to a significant decline in the tribological properties of AAO. The average depth, width and wear rate of the wear track were $4.18 \mu \mathrm{m}, 401.9 \mu \mathrm{m}$ and $3.84 \pm 0.14 \mathrm{~mm}^{3} \cdot \mathrm{N}^{-1} \cdot \mathrm{m}^{-1}$, respectively, as shown in Figure $7 \mathrm{c}, \mathrm{d}$. 

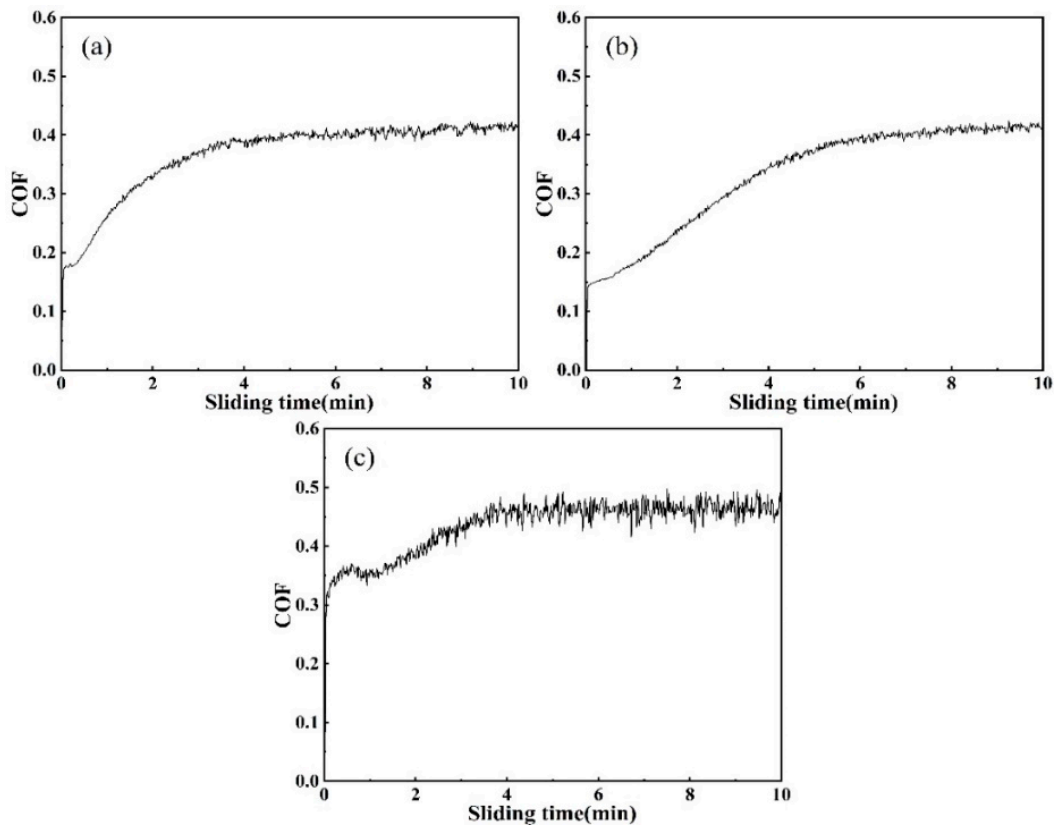

Figure 6. Friction coefficient evolution for $(\mathbf{a}) 5^{\circ} \mathrm{C},(\mathbf{b}) 15^{\circ} \mathrm{C},(\mathbf{c}) 25^{\circ} \mathrm{C}$.
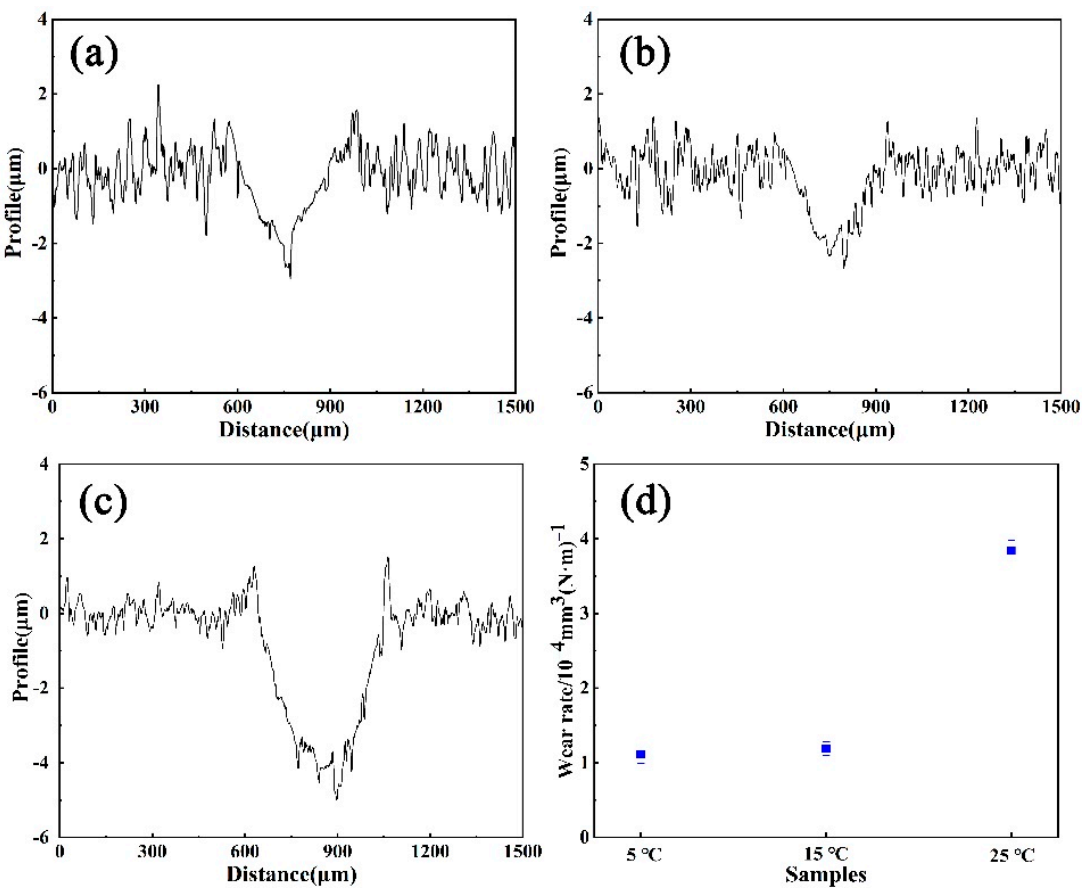

Figure 7. Cross-sectional morphology and wear rate of the AAO wear scar: (a) $5{ }^{\circ} \mathrm{C}$, (b) $15^{\circ} \mathrm{C}$, (c) $25^{\circ} \mathrm{C},(\mathbf{d})$ wear rate.

\section{Conclusions}

In this paper, the effect of electrolyte temperature on the surface microstructure of 6061 aluminum alloy anodic oxide films (AAO) was investigated, followed by the hardness and elastic modulus of the films, and the tribological properties of the films were studied. The main conclusions are as follows.

The AAO prepared in the electrolyte at $5{ }^{\circ} \mathrm{C}$ had a dense pore wall structure capable of maintaining a high hardness. The AAO had regular holes with diameters of about 6-12 nm, and the composition of the AAO was amorphous oxide layers. When the electrolyte 
temperature reached $25^{\circ} \mathrm{C}$, coral-like loose porous structures appeared on the surface of the AAO, which had a negative impact on the hardness and elastic modulus of the films.

The friction coefficient of AAO decreased with the decrease of electrolyte temperature. The loose AAO prepared at $25^{\circ} \mathrm{C}$ had a thick friction layer in the wear track under $5 \mathrm{~N}$ load, and the friction mechanism was delamination wear dominated by flake or block shedding. As the temperature decreased, the worn form changed from delamination wear to abrasive and adhesive wear, and the wear resistance of the films was significantly improved. Finally, dense AAO prepared at $5{ }^{\circ} \mathrm{C}$ had excellent anti-friction and anti-wear properties.

Author Contributions: Conceptualization, Y.C. (Yongzhi Cao); methodology, Y.C. (Yaowen Cui) and Z.X.; formal analysis, Z.H.; writing-original draft preparation, F.G.; writing-review and editing, K.W.; supervision, P.Z. All authors have read and agreed to the published version of the manuscript.

Funding: This research was funded by the NSAF (No. U2030109), the Fundamental Research Funds for the Central Universities (HIT.OCEF.2021002).

Institutional Review Board Statement: Not applicable.

Informed Consent Statement: Not applicable.

Data Availability Statement: No new data were created or analyzed in this study. Data sharing is not applicable to this article.

Conflicts of Interest: The authors declare no conflict of interest.

\section{References}

1. Kareem, A.; Abu Qudeiri, J.; Abdudeen, A.; Ahammed, T.; Ziout, A. A Review on AA 6061 Metal Matrix Composites Produced by Stir Casting. Materials 2021, 14, 175. [CrossRef] [PubMed]

2. Baghdadi, A.H.; Sajuri, Z.; Keshtgar, A.; Sharif, N.M.; Rajabi, A. Mechanical Property Improvement in Dissimilar Friction Stir Welded Al5083/Al6061 Joints: Effects of Post-Weld Heat Treatment and Abnormal Grain Growth. Materials 2021, 15, 288. [CrossRef] [PubMed]

3. Kotomin, E.A.; Kuzovkov, V.; Popov, A.I.; Vila, R. Kinetics of F center annealing and colloid formation in $\mathrm{Al}_{2} \mathrm{O}_{3}$. Nucl. Instrum. Methods Phys. Res. Sect. B Beam Interact. Mater. At. 2016, 374, 107-110. [CrossRef]

4. Averback, R.S.; Ehrhart, P.; Popov, A.I.; Sambeek, A.V. Defects in ion implanted and electron irradiated $\mathrm{Mgo}$ and $\mathrm{Al}_{2} \mathrm{O}_{3}$. Radiat Eff. Defects Solids 1995, 136, 169-173. [CrossRef]

5. Zhang, P.; Zuo, Y. Effects of pore parameters on performance of anodic film on 2024 aluminum alloy. Mater. Chem. Phys. 2019, 231, 9-20. [CrossRef]

6. Cirik, E.; Genel, K. Effect of anodic oxidation on fatigue performance of 7075-T6 alloy. Surf. Coatings Technol. 2008, $202,5190-5201$. [CrossRef]

7. Fiore, V.; Di Franco, F.; Miranda, R.; Santamaria, M.; Badagliacco, D.; Valenza, A. Effects of anodizing surface treatment on the mechanical strength of aluminum alloy 5083 to fibre reinforced composites adhesive joints. Int. J. Adhes. Adhes. 2021, 108, 102868. [CrossRef]

8. Franco, M.; Krishna, T.H.; Pillai, A.M.; Rajendra, A.; Sharma, A.K. A comparative study on the corrosion behaviour of hard anodic coatings on AA 6061 obtained using DC and pulsed DC power sources. Acta Met. Sin. 2013, 26, 647-656. [CrossRef]

9. Rajasekaran, B.; Raman, S.G.S.; Krishna, L.R.; Joshi, S.; Sundararajan, G. Influence of microarc oxidation and hard anodizing on plain fatigue and fretting fatigue behaviour of Al-Mg-Si alloy. Surf. Coat. Technol. 2008, 202, 1462-1469. [CrossRef]

10. Thompson, G.E.; Habazaki, H.; Shimizu, K.; Sakairi, M.; Skeldon, P.; Zhou, X.; Wood, G.C. Anodizing of aluminium alloys. Aircr Eng. Aerosp. Technol. 1999, 71, 228-238. [CrossRef]

11. Keller, F.; Hunter, M.S.; Robinson, D.L. Structural Features of Oxide Coatings on Aluminum. J. Electrochem. Soc. 1953, 100, 411-419. [CrossRef]

12. Lee, S.; Kim, D.; Kim, Y.; Jung, U.; Chung, W. Effect of aluminum anodizing in phosphoric acid electrolyte on adhesion strength and thermal performance. Met. Mater. Int. 2016, 22, 20-25. [CrossRef]

13. Ali, I.; Quazi, M.M.; Zalnezhad, E.; Sarhan, A.A.D.; Sukiman, N.L.; Ishak, M. Hard Anodizing of Aerospace AA7075-T6 Aluminum Alloy for Improving Surface Properties. Trans. Indian Inst. Met. 2019, 72, 2773-2781. [CrossRef]

14. Tian, L.-P.; Zuo, Y.; Zhao, X.-H.; Zhao, J.-M.; Xiong, J.-P. The improved corrosion resistance of anodic films on aluminum by nickel ions implantation. Surf. Coat. Technol. 2006, 201, 3246-3252. [CrossRef]

15. Zhao, Y.; Chen, M.; Zhang, Y.; Xu, T.; Liu, W. A facile approach to formation of through-hole porous anodic aluminum oxide film. Mater. Lett. 2005, 59, 40-43. [CrossRef]

16. Aerts, T.; Dimogerontakis, T.; De Graeve, I.; Fransaer, J.; Terryn, H. Influence of the anodizing temperature on the porosity and the mechanical properties of the porous anodic oxide film. Surf. Coat. Technol. 2007, 201, 7310-7317. [CrossRef] 
17. Kim, H.-S.; Kim, D.-H.; Lee, W.; Cho, S.J.; Hahn, J.-H.; Ahn, H.-S. Tribological properties of nanoporous anodic aluminum oxide film. Surf. Coatings Technol. 2010, 205, 1431-1437. [CrossRef]

18. Kim, M.; Choi, E.; So, J.; Shin, J.-S.; Chung, C.-W.; Maeng, S.-J.; Yun, J.-Y. Improvement of corrosion properties of plasma in an aluminum alloy 6061-T6 by phytic acid anodization temperature. J. Mater. Res. Technol. 2020, 11, 219-226. [CrossRef]

19. Theohari, S.; Kontogeorgou, C. Effect of temperature on the anodizing process of aluminum alloy AA 5052. Appl. Surf. Sci. 2013, 284, 611-618. [CrossRef]

20. Knörnschild, G.; Poznyak, A.; Karoza, A.; Mozalev, A. Effect of the anodization conditions on the growth and volume expansion of porous alumina films in malonic acid electrolyte. Surf. Coat. Technol. 2015, 275, 17-25. [CrossRef]

21. Wang, Z.; Lei, Y.; Chen, K.; Li, Q.; Yin, Y.; Fam, R. Effect of Oxidation Treatment on Microstructure and Electrochemical Properties of 6061 Aluminum Alloy. Int. J. Electrochem. Sci. 2021, 16, 210243. [CrossRef]

22. Cheng, T.-C.; Chou, C.-C. The Electrical and Mechanical Properties of Porous Anodic 6061-T6 Aluminum Alloy Oxide Film. J. Nanomater. 2015, 2015, 371405. [CrossRef]

23. Chung, I.; Chung, C.-K.; Su, Y. Effect of current density and concentration on microstructure and corrosion behavior of $6061 \mathrm{Al}$ alloy in sulfuric acid. Surf. Coat. Technol. 2017, 313, 299-306. [CrossRef]

24. Mohitfar, S.H.; Mahdavi, S.; Etminanfar, M.; Khalil-Allafi, J. Characteristics and tribological behavior of the hard anodized 6061-T6 Al alloy. J. Alloy. Compd. 2020, 842, 155988. [CrossRef]

25. Krishna, L.R.; Purnima, A.S.; Sundararajan, G. A comparative study of tribological behavior of microarc oxidation and hardanodized coatings. Wear 2006, 261, 1095-1101. [CrossRef]

26. Fratila-Apachitei, L.E.; Duszczyk, J.; Katgerman, L. AlSi(Cu) anodic oxide layers formed in $\mathrm{H}_{2} \mathrm{SO}_{4}$ at low temperature using different current waveforms. Surf. Coat. Technol. 2003, 165, 232-240. [CrossRef]

27. Garcia-Vergara, S.; Skeldon, P.; Thompson, G.; Habazaki, H. A flow model of porous anodic film growth on aluminium. Electrochim. Acta 2006, 52, 681-687. [CrossRef]

28. Garcia-Vergara, S.J.; Habazaki, H.; Skeldon, P.; Thompson, G.E. Formation of porous anodic alumina at high current efficiency. Nanotechnology 2007, 18, 415605. [CrossRef]

29. Lee, W.; Scholz, R.; Gösele, U. A Continuous Process for Structurally Well-Defined Al2O3 Nanotubes Based on Pulse Anodization of Aluminum. Nano Lett. 2008, 8, 2155-2160. [CrossRef] [PubMed]

30. Patermarakis, G. Development of a theory for the determination of the composition of the anodizing solution inside the pores during the growth of porous anodic $\mathrm{Al}_{2} \mathrm{O}_{3}$ films on aluminium by a transport phenomenon analysis. J. Electroanal. Chem. 1998, 447, 25-41. [CrossRef]

31. Camargo, A.; Voorwald, H. Influence of anodization on the fatigue strength of 7050-T7451 aluminium alloy. Fatigue Fract. Eng. Mater. Struct. 2007, 30, 993-1007. [CrossRef] 